\title{
Prevalence of sleep-related symptoms in a primary care population - their relation to asthma and COPD
}

\section{Foteini Karachaliou ${ }^{a}$ * Konstantinos Kostikas ${ }^{\mathrm{b}}$, Chaido Pastakab, Vassilios Bagiatisc, Konstantinos I Gourgoulianis ${ }^{d}$}

\footnotetext{
${ }^{a}$ Resident in Primary Health Care, University Hospital of Larissa, Greece

${ }^{b}$ Consultant Physician, Respiratory Medicine Department, University of Thessaly Medical School, Larissa, Greece

c Lecturer, Department of Biochemistry and Biotechnology, University of Thessaly, Greece

d Professor of Respiratory Medicine, University of Thessaly Medical School, Greece
}

Received 4th October 2006; accepted 22nd March 2007

\begin{abstract}
Aims: The aim of this study was to clarify the association between obstructive sleep apnoea/hypopnoea syndrome (OSAHS)-related symptoms and physician-diagnosed asthma and COPD.

Methods: 1501 subjects aged 19-90 years completed a structured questionnaire and underwent spirometry and respiratory physician assessment in 10 primary care centres.

Results: Frequent snoring was reported in $45.6 \%$, breathing pauses during sleep in $11.0 \%$, and excessive daytime sleepiness in $6.7 \%$ of the sample. COPD patients were more likely to report frequent snoring ( $\mathrm{OR}=1.34 ; 95 \% \mathrm{Cl}: 1.04-1.71)$, breathing pauses (OR=1.46; $95 \%$ $\mathrm{Cl}: 1.01-2.10)$, and excessive daytime sleepiness ( $\mathrm{OR}=2.04 ; 95 \% \mathrm{Cl}: 1.33-3.14)$. In contrast, there was no significant association between asthma patients and OSAHS-related symptoms. Gender differences were recognised as well.

Conclusions: The increased likelihood for OSAHS-related symptoms in COPD patients, in contrast to patients with asthma, designates them as a target group for the screening of OSAHS in primary care.

(C) 2007 General Practice Airways Group. All rights reserved

F Karachaliou, et al. Prim Care Resp J 2007; 16(4): 222-228

doi:10.3132/pcrj.2007.00045
\end{abstract}

Keyw ords obstructive sleep apnoea/hypopnoea syndrome, asthma, chronic obstructive pulmonary disease, snoring, sleepiness

\section{Introduction}

The obstructive sleep apnoea/hypopnoea syndrome (OSAHS) is a condition characterised by recurrent episodes of upper airway obstruction during sleep.' The most common clinical presentations of OSAHS include snoring, breathing pauses observed by the patient's bed partner, and daytime sleepiness. ${ }^{2}$ This syndrome is often underdiagnosed, since less than $10 \%$ of patients with significant OSAHS are recognised. ${ }^{3}$ Reasons for the underdiagnosis include the limited education of doctors in sleep disorders and patients' inability to inform doctors about sleep problems. ${ }^{4}$

OSAHS has been associated with many medical problems. Lately, epidemiological studies have demonstrated a positive connection between obstructive sleep apnoea and cardiovascular diseases (CVD). ${ }^{5}$ OSAHS often coexists with COPD, and this coexistence has been confirmed in epidemiological studies. ${ }^{6}$ An association of snoring and breathing pauses in subjects with asthma-related symptoms has also been reported, ${ }^{7,8}$ but these results were not confirmed in other studies. ${ }^{9}$

OSAHS - especially if there is excessive daytime sleepiness - has been associated with workplace problems and motor vehicle accidents, resulting in diminished quality of life and increased morbidity and mortality. ${ }^{10}$ The early detection of OSAHS-related symptoms by primary care physicians may be essential in order to reduce co-morbidity and the burden on public health services. Only a few studies in the literature have focused on screening for OSAHS-related symptoms in primary

\footnotetext{
* Corresponding author: University Hospital of Larissa, Larissa 41110, Greece
}

Tel: +30-6944780616 E-mail: ktk@otenet.gr, kkostik@med.uth.gr 
care, and even less on the relation of such symptoms to other major respiratory disorders, such as asthma and COPD.

The aim of the present study was to estimate the prevalence of OSAHS-related symptoms and risk factors in a population of Greek adults visiting primary care offices, and to determine whether these symptoms were associated with a physician-confirmed diagnosis of asthma or COPD. The secondary aims of this study were to assess differences in OSAHS-related symptoms between different genders and in patients with a history of hypertension, CVD and stroke.

\section{Materials and methods}

The study was conducted over a 1-year period (from January 2004 to February 2005) in 10 primary care centres in Greece. Subjects included in the study were Greek residents, aged 1990 years old, who visited primary care doctors for any reason. The study population was a random sample of the patients attending each primary care centre. The study co-ordinators visited each primary care centre on the first five working days of one month. Participation in the study was offered to 1821 patients who attended the primary care centres on these days and 1501 patients agreed to participate in the study - a response rate of $82.4 \%$. A structured questionnaire was completed for all patients. Subsequently, all patients were subjected to spirometry, and assessment of body mass index (BMI) by measuring their weight and height and expressing it in $\mathrm{kg} / \mathrm{m}^{2}$. The demographic characteristics of the study participants are shown in Table 1.

\section{Study questionnaire}

A questionnaire was used to collect demographic information and past medical history, including smoking habit, hypertension, CVD (congestive heart failure, coronary artery disease, and arrhythmias), and stroke, as well as other significant co-morbidities (e.g. diabetes, hypothyroidism, depression, and use of medication). Medical records and prescribing records were reviewed in the majority of the patients who participated in the study, in order to validate the presence of co-morbidities. Specific questions about symptoms related to asthma and COPD were also included; patients were asked if they had any of the following symptoms during the past year - cough, sputum production, shortness of breath while exercising or during sleep, or wheezing. Questions about asthma attacks or use of asthma medication, and allergic rhinitis, were also included.

Subsequently, participants underwent an interview by physicians specially trained in respiratory and sleep disorders. Two instruments were used for identification of OSAHS symptoms;

- symptoms related to OSAHS were assessed using the Berlin Questionnaire," which has been previously used in epidemiological studies in primary care. This questionnaire
Table 1. Demographic data of the study participants.

\begin{tabular}{|c|c|c|}
\hline Characteristic & Data & $(\%)$ \\
\hline Gender & 1501 & \\
\hline Male & 892 & 59.4 \\
\hline Female & 609 & 40.6 \\
\hline Age (years) & $60.7 \pm 14.3$ & \\
\hline$<45 y$ & 278 & 18.5 \\
\hline $46-65 y$ & 522 & 34.8 \\
\hline$>66 y$ & 701 & 46.7 \\
\hline $\mathrm{BMI}\left(\mathrm{kg} / \mathrm{m}^{2}\right)$ & $28.9 \pm 4.7$ & \\
\hline$<30 \mathrm{~kg} / \mathrm{m}^{2}$ & 951 & 63.4 \\
\hline$\geq 30 \mathrm{kgr} / \mathrm{m}^{2}$ & 550 & 36.6 \\
\hline \multicolumn{3}{|l|}{ Smoking status } \\
\hline Current & 537 & 35.8 \\
\hline Former & 271 & 18.1 \\
\hline Never & 693 & 46.2 \\
\hline Hypertension & 716 & 47.7 \\
\hline Cardiovascular diseases* & 270 & 17.1 \\
\hline Stroke & 54 & 3.5 \\
\hline COPD & 323 & 21.5 \\
\hline Stage I $\left(F E V_{1} \geq 80 \%\right)$ & 93 & 6.1 \\
\hline Stage II (FEV $150-79 \%)$ & 172 & 11.4 \\
\hline Stage III (FEV $130-49 \%)$ & 49 & 3.2 \\
\hline Stage IV $\left(\mathrm{FEV}_{1}<30 \%\right)$ & 9 & 0.5 \\
\hline Asthma & 218 & 14.5 \\
\hline
\end{tabular}

has increased sensitivity and specificity for the identification of patients with clinically significant OSAHS, i.e. an apnoea/ hypopnoea index $>5$ events/hour in a sleep study. It includes questions about snoring, witnessed apnoeas, tiredness, history of high blood pressure and/or BMl $>30 \mathrm{~kg} / \mathrm{m}^{2}$. Positive answers to two of the three categories of the questionnaire indicate a high pre-test probability for OSAHS.

- subjective daytime sleepiness was assessed with the Epworth Sleepiness Scale (ESS); scores $\geq 10$ are consistent with excessive daytime sleepiness. ${ }^{12}$

\section{Spirometry}

Spirometry was performed with a dry spirometer (Koko Legend, Ferraris Louisville, CO, USA) according to American Thoracic Society (ATS) Guidelines. ${ }^{13}$ Forced expiratory volume in one second $\left(\mathrm{FEV}_{1}\right)$, forced vital capacity $(\mathrm{FVC})$, and their ratio $\left(F E V_{1} / F V C\right)$, were measured. All subjects with $\mathrm{FEV}_{1}$ $<80 \%$ of the predicted value and/or $\mathrm{FEV}_{1} / \mathrm{FVC}<70 \%$ were 
Table 2. Distribution of responses according to gender and age. Data are presented as actual numbers with percentages in the specific age group in parentheses.

\begin{tabular}{|c|c|c|c|c|c|c|c|c|}
\hline \multirow[b]{2}{*}{ Age Groups } & \multicolumn{4}{|c|}{ MEN } & \multicolumn{4}{|c|}{ WOMEN } \\
\hline & $19-45$ & $46-65$ & $66+$ & Total & $19-45$ & $46-65$ & $66+$ & Total \\
\hline \multicolumn{9}{|l|}{ Snoring Frequency } \\
\hline Almost every day & $34(18.4)$ & $81(30.9)$ & $149(33.4)$ & $264(29.5)$ & $10(10.6)$ & $66(25.3)$ & $71(31.5)$ & $147(24.1)$ \\
\hline 3-4 times/wk & $33(17.9)$ & $61(23.2)$ & $80(17.9)$ & $174(19.5)$ & 15(15.9) & $40(15.3)$ & $45(20.0)$ & $100(16.4)$ \\
\hline 1-2 times/wk & $21(11.4)$ & $16(6.1)$ & $33(7.3)$ & $70(7.8)$ & $5(5.3)$ & $19(7.3)$ & $21(9.3)$ & $45(7.3)$ \\
\hline 1-2 times/mo & $26(14.1)$ & $31(11.8)$ & $46(10.3)$ & $103(11.2)$ & $16(17.0)$ & $32(12.3)$ & $29(12.8)$ & $77(12.6)$ \\
\hline Never or almost never & $70(38.0)$ & $73(27.8)$ & 138(30.9) & $281(31.5)$ & $48(51.0)$ & 103(39.6) & $89(39.5)$ & $240(39.4)$ \\
\hline \multicolumn{9}{|l|}{ ESS } \\
\hline $0-9$ & 178(96.7) & $240(91.6)$ & $400(89.6)$ & $818(91.7)$ & 93(98.9) & 249(95.7) & $240(94.1)$ & $582(95.5)$ \\
\hline$\geq 10$ & $6(3.2)$ & $22(8.3)$ & $46(10.3)$ & $74(8.2)$ & $1(1.1)$ & $11(4.2)$ & $15(5.8)$ & $27(4.4)$ \\
\hline \multicolumn{9}{|l|}{ Witnessed apnoeas } \\
\hline yes & 19(10.3) & $47(17.9)$ & $57(12.7)$ & $123(13.7)$ & $5(5.3)$ & $21(8.1)$ & $17(6.7)$ & $43(7.1)$ \\
\hline no & 165(89.6) & $215(82.0)$ & $389(87.2)$ & $769(86.2)$ & $89(94.6)$ & 239(91.9) & 238(93.3) & $566(92.9)$ \\
\hline \multicolumn{9}{|l|}{$\mathrm{BMI}>30 \mathrm{kgr} / \mathrm{m}^{2}$} \\
\hline yes & $49(26.6)$ & $90(34.3)$ & $146(32.7)$ & 285(31.9) & $26(27.6)$ & $126(48.5)$ & $126(49.4)$ & $278(45.6)$ \\
\hline no & 135(73.4) & $172(65.6)$ & $300(67.2)$ & $607(68.1)$ & $68(72.3)$ & $134(51.5)$ & 129(50.6) & $331(54.3)$ \\
\hline \multicolumn{9}{|l|}{ Hypertension } \\
\hline yes & $12(6.5)$ & $93(35.4)$ & $304(68.1)$ & $409(45.8)$ & $4(4.2)$ & $112(43.0)$ & 191(74.9) & $307(50.4)$ \\
\hline no & $172(93.5)$ & $169(64.5)$ & $142(31.8)$ & $483(51.4)$ & $90(95.8)$ & $148(56.9)$ & $64(25.0)$ & $302(49.6)$ \\
\hline \multicolumn{9}{|l|}{ History of CVD* } \\
\hline yes & $0(0.0)$ & $37(14.1)$ & $147(32.9)$ & 184(20.6) & $0(0.0)$ & $18(6.9)$ & $68(26.6)$ & $86(14.1)$ \\
\hline no & $184(100.0)$ & $225(85.8)$ & 299(67.0) & 708(79.3) & $94(100.0)$ & $242(93.1)$ & 187(73.3) & $523(85.9)$ \\
\hline \multicolumn{9}{|l|}{ History of stroke } \\
\hline yes & $1(0.5)$ & $6(2.2)$ & $35(7.8)$ & $42(4.7)$ & $0(0.0)$ & $7(2.6)$ & $5(1.9)$ & $12(2.0)$ \\
\hline no & 183(99.5) & 256(97.7) & $411(92.1)$ & $850(95.3)$ & $94(100.0)$ & 253(97.3) & 250(98.0) & $597(98.0)$ \\
\hline \multicolumn{9}{|l|}{ COPD } \\
\hline yes & $19(10.3)$ & $73(27.8)$ & $205(80.3)$ & 297(33.3) & $3(3.2)$ & $15(5.7)$ & $8(3.1)$ & $26(4.3)$ \\
\hline no & 165(89.6) & 189(72.1) & $241(94.5)$ & 595(66.7) & $91(96.8)$ & $245(94.2)$ & 247(96.8) & $583(95.7)$ \\
\hline \multicolumn{9}{|l|}{ Asthma } \\
\hline yes & $9(4.9)$ & $17(6.5)$ & $47(10.5)$ & $73(8.2)$ & 13(13.8) & $62(23.8)$ & $70(27.4)$ & $145(23.8)$ \\
\hline no & 175(95.1) & $245(93.5)$ & 399(89.4) & 819(91.8) & $81(86.2)$ & 198(76.1) & $185(72.5)$ & $464(76.2)$ \\
\hline
\end{tabular}

${ }^{*}$ CVD: cardiovascular diseases (including coronary artery disease, arrhythmias and congestive heart failure).

subsequently subjected to bronchodilator reversibility testing, according to GOLD guidelines. ${ }^{14}$

\section{Diagnosis of asthma and COPD}

The diagnoses of COPD and asthma were confirmed by two respiratory physicians who were present throughout the study. The diagnosis of COPD was based on the presence of an obstructive pattern in spirometry (i.e. post-bronchodilator $\mathrm{FEV}_{1} / \mathrm{FVC}<70 \%$ ) in patients with a smoking history $>30$ pack-years, in accordance with the GOLD guidelines. ${ }^{14}$ The differentiation of asthmatic and COPD patients was based on 
the following criteria: ${ }^{15}$ (a) asthmatic subjects had a longstanding history of asthma from their childhood or adolescence whereas COPD patients had a later onset of symptoms which were closely related to smoking; (b) a history of atopy (e.g. seasonal symptoms, allergic rhinitis) was considered indicative of asthma; (c) significant reversibility of airway obstruction on spirometry (i.e. increase of at least $12 \%$ and $200 \mathrm{~mL}$ in baseline $\mathrm{FEV}_{1}$ after administration of $400 \mu \mathrm{g}$ salbutamol) was considered indicative of asthma.

\section{Statistical analysis}

Statistical analysis was performed by using SPSS (v.12.0; SPSS, Inc.; Chicago, IL). Normality of distribution of data was tested with the Kolmogorov-Smirnov test. Demographic data and prevalence rates of sleep-related symptoms and comorbidities were described using frequency distributions and proportions, whereas quantitative variables were expressed as mean $\pm S D$. Comparison between categorical variables was performed with chi-square tests, whereas comparisons between continuous variables were performed with unpaired t-tests or Mann-Whitney U-tests, as appropriate. P values $<0.05$ were considered statistically significant.

For the evaluation of possible differences in BMI and sleep-related symptoms according to gender, respiratory (asthma or COPD), and cardiovascular (hypertension, coronary artery disease or stroke) co-morbidities, logistic regression was applied. Dichotomisation of variables was performed as follows: patients snoring "almost every day" and "3-4 times/week" were considered as "frequent snorers", whereas those snoring "1-2 times/week", "1-2 times/month" and "never or almost never" were considered as "occasional snorers"; subjective sleepiness (ESS $<10$ or ESS $\geq 10)$; BMI $\left(<30 \mathrm{~kg} / \mathrm{m}^{2}\right.$ or $\left.\geq 30 \mathrm{~kg} / \mathrm{m}^{2}\right)$; gender (male/female); hypertension (yes/no); CVD (yes/no); stroke (yes/no); COPD (yes/no); and asthma (yes/no). Age was divided using the following cut-off points: $19-45$ years, $46-65$ years, and $\geq 66$ years; this was performed in order to obtain roughly equal groups. Rate differences between groups were calculated by odds ratios (OR) and the corresponding 95\% confidence intervals $(\mathrm{Cl})$.

\section{Results}

Patients' demographics are presented in Table 1 and the distribution of responses among age and gender groups in Table 2. Males and females did not differ with respect to age (men, 60.9 \pm 15.4 years; women, $60.3 \pm 12.6$ years; $p=0.38$ ). Men reported higher levels of current smoking ( $48.7 \%$ vs. $18.7 \%$, respectively; $p<0.001)$ and lower $\mathrm{BMI}(28.4 \pm 4.1$ $\mathrm{kg} / \mathrm{m}^{2}$ vs. $\left.29.6 \pm 5.3 \mathrm{~kg} / \mathrm{m}^{2} ; \mathrm{p}<0.001\right)$ compared to women. A diagnosis of COPD was more common in men than women ( $33.3 \%$ vs. $4.3 \%$, respectively; $p<0.001)$, whereas a diagnosis of asthma was more common in women compared to men
Figure 1. OR comparisons between COPD and nonCOPD patients with regard to OSAHS-related symptoms and obesity. An OR $>1$ indicates greater likelihood for COPD patients. Bars represent $95 \%$ confidence intervals (CI).

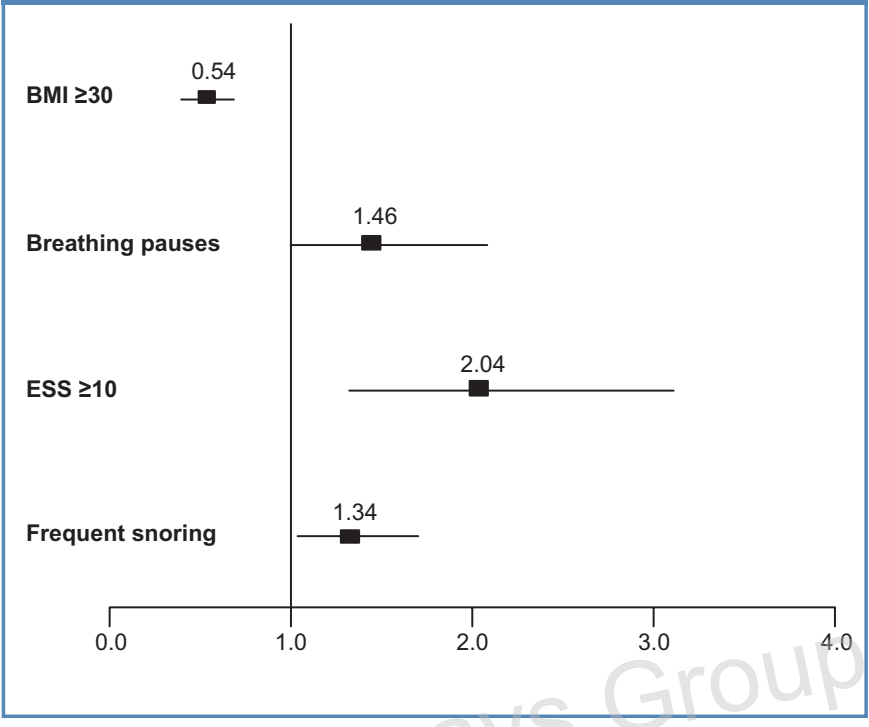

Figure 2. OR comparisons between asthmatics and nonasthmatics patients with regard to OSAHS- related symptoms and obesity. An OR >1 indicates greater itkelihood for asthmatic patients. Bars represent $95 \%$ confidence intervals (Cl).

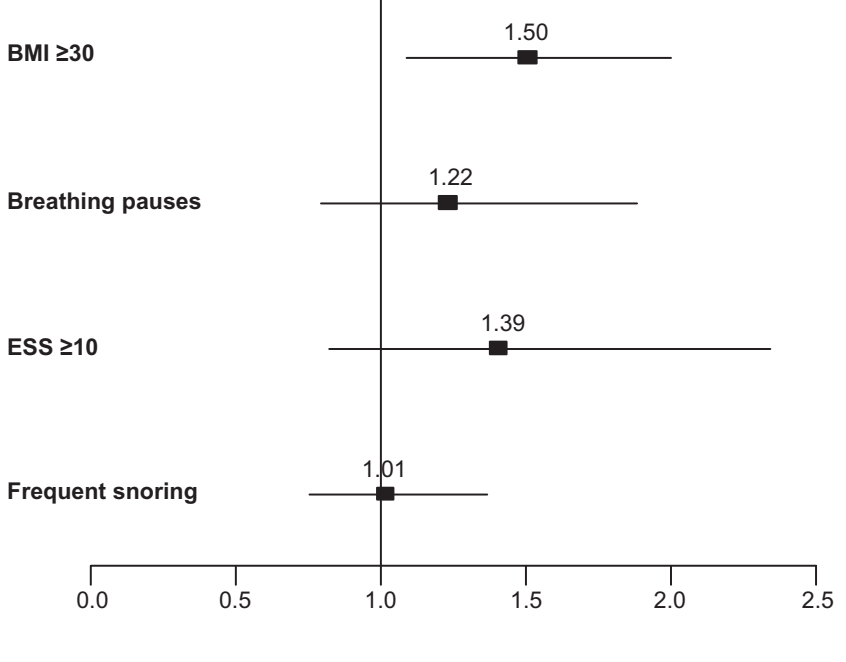

$(23.8 \%$ vs. $8.2 \%$, respectively; $\mathrm{p}<0.001)$. A history of hypertension did not differ between the two genders (45.8\% vs. $50.4 \%$, respectively; $p=0.09$ ), but men reported more frequently a history of CVD $(20.6 \%$ vs. $14.1 \% ; p=0.002)$ and a history of stroke $(4.7 \%$ vs. $2.0 \% ; p=0.008)$. 
Figure 3. OR comparisons between men and women with regard to OSAHS-symptoms and obesity. An OR $>1$ indicates greater likelihood for men. Bars represent $95 \%$ confidence intervals (CI).

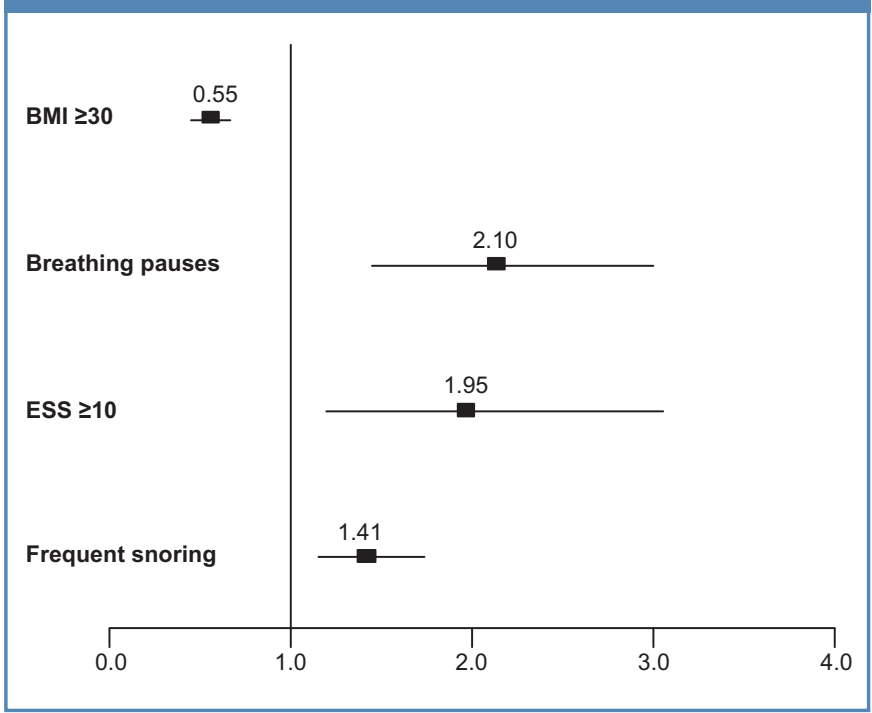

Frequent snoring (>3 nights/week) was reported in $45.6 \%$ of the study population, breathing pauses during sleep as witnessed by the participants' bed partners in $11.0 \%$, and excessive daytime sleepiness ( $E S S \geq 10$ ) in $6.7 \%$ of the sample.

\section{Sleep-related symptoms and obesity in patients with COPD}

Sleep-related symptoms were more prevalent in COPD patients. Specifically, COPD patients were more likely to report frequent snoring $(\mathrm{OR}=1.34 ; \mathrm{Cl}: 1.04-1.71)$, breathing pauses $(\mathrm{OR}=1.46 ; \mathrm{Cl}: 1.01-2.10)$, and excessive daytime sleepiness $(\mathrm{OR}=2.04 ; \mathrm{Cl}: 1.33-3.14)$. These findings again were observed despite the fact that COPD patients were less likely to be obese $(\mathrm{OR}=0.54 ; \mathrm{Cl}: 0.41-0.71)$ - Figure 1. No differences were observed in the likelihood for sleep-related symptoms between COPD patients with different disease severities.

\section{Sleep-related symptoms and obesity in patients with asthma}

Subjects with a diagnosis of asthma were more likely to be obese (OR=1.50; $\mathrm{Cl}: 1.12-2.04)$, but there was no association with snoring $(\mathrm{OR}=1.01 ; \mathrm{Cl}: 0.76-1.35)$, breathing pauses $(\mathrm{OR}=1.22 ; \mathrm{Cl}: 0.79-1.88)$, and excessive daytime sleepiness $(\mathrm{OR}=1.39 ; \mathrm{Cl}: 0.83-2.35)$ in these patients - Figure 2.

\section{Sleep-related symptoms and obesity in patients with a history of hypertension, CVD, and stroke}

Patients with a history of hypertension were almost twice as likely to present excessive daytime sleepiness $(\mathrm{OR}=1.81$; $\mathrm{Cl}$ : 1.19-2.74). They were also more likely to be frequent snorers $(\mathrm{OR}=1.72 ; \mathrm{Cl}: 1.40-2.11)$ and obese $(\mathrm{OR}=1.93 ; \mathrm{Cl}: 1.56-2.38)$. However, hypertension was not associated with breathing pauses (OR=1.02; $\mathrm{Cl}$ : 0.74-1.41).
Patients with a history of CVD were twice as likely to present excessive daytime sleepiness ( $\mathrm{OR}=2.04 ; \mathrm{Cl}: 1.30-3.19)$, and were more likely to present frequent snoring $(\mathrm{OR}=1.51 ; \mathrm{Cl}: 1.16-1.96)$ and obesity (OR=1.37; $\mathrm{Cl}: 1.04-1.79)$. There was no association between CVD and breathing pauses ( $\mathrm{OR}=1.25$; $\mathrm{Cl}$ : 0.83-1.86).

Patients with a history of stroke were more likely to present frequent snoring (OR=1.91; Cl: 1.09-3.34). However, a history of stroke was not associated with excessive daytime sleepiness $(\mathrm{OR}=1.71 ; \mathrm{Cl}$ : 0.74-4.26), breathing pauses $(\mathrm{OR}=1.88 ; \mathrm{Cl}$ : $0.92-3.80)$, or obesity (OR=0.97; $\mathrm{Cl}: 0.55-1.71)$.

\section{Differences in sleep-related symptoms and obesity betw een genders}

Differences in symptom frequencies between men and women are presented in Table 2 . Men reported frequent snoring more often than women $(\mathrm{OR}=1.41 ; \mathrm{Cl}: 1.14-1.74) ;$ men were additionally twice more likely to present breathing pauses $(\mathrm{OR}=2.10 ; \mathrm{Cl}: 1.46-3.02)$ and excessive daytime sleepiness $(\mathrm{OR}=1.95 ; \mathrm{Cl}: 1.23-3.06)$ than women. These differences were observed despite the fact that men were less likely to be obese compared to women ( $\mathrm{OR}=0.55 ; \mathrm{Cl}:$ 0.45-0.69 - Figure 3).

\section{Discussion}

In this cross-sectional study conducted in primary care centres in Greece we have shown that OSAHS-related symptoms (i.e. frequent snoring, excessive daytime sleepiness and breathing pauses) that present a high pre-test probability for the diagnosis of OSAHS are more frequent in patients with COPD, whereas no such association was observed in patients with asthma. Additionally, patients with a history of hypertension, CVD or stroke were more likely to present frequent snoring, whereas excessive daytime sleepiness was associated only with a past history of hypertension or CVD. Breathing pauses were not related to hypertension, CVD or stroke. Finally, OSAHS-related symptoms were more frequent in men compared to women. These results correspond to a large random sample of the population attending primary care centres in Greece, and given the relatively high response rate of $82.4 \%$, they may reflect the prevalence of OSAHS-related symptoms in this population.

To our knowledge, this is the first study to assess OSAHSrelated symptoms in patients with a diagnosis of asthma or COPD confirmed by respiratory physicians. COPD patients in our population presented a higher prevalence of OSAHSrelated symptoms. These results are in accordance with the findings of a previous postal survey, reporting that OSAHS symptoms were more common in subjects with chronic bronchitis. ${ }^{6}$ Numerous studies have shown that OSAHS patients diagnosed in a sleep laboratory often present with coexisting COPD, with a prevalence of overlap ranging from $11 \%$ to $16 \% .{ }^{16,17}$ The present study has shown that COPD patients are twice as likely to present daytime sleepiness and, 
additionally, are more likely to present frequent snoring or breathing pauses, compared to non-COPD subjects. The absence of any difference in the likelihood of sleep-related symptoms in patients with different COPD severities may be attributed to the fact that the majority of our patients had mild-to-moderate COPD. Interestingly, the increased prevalence of these symptoms was evident despite the fact that our COPD patients were less likely to be obese compared to the general population.

Possible explanations for the relationship between COPD and OSAHS-related symptoms include sleep-related hypoxemia that is often present in patients with COPD and could contribute to daytime sleepiness in such patients; alternatively, the coexistence of an underlying sleep disorder, most likely obstructive sleep apnoea, might account for these symptoms. Although many COPD patients complained of poor quality of sleep in the Sleep Heart Health Study, ${ }_{18}$ in fact patients with mild COPD without sleep apnoea/hypopnoea syndrome had minimally perturbed sleep, indicating that mild COPD per se affects minimally the quality of sleep. In contrast, the coexistence of COPD and OSAHS was associated with increased sleep desaturations, ${ }^{18}$ plausibly leading to more severe daytime symptoms. Smoking may represent a common risk factor for both conditions. ${ }^{19}$

In the present study, no significant association was found between sleep-related symptoms and physician-diagnosed asthma. These findings are inconsistent with the findings of a population-based cross-sectional study by Ekici and coworkers, ${ }^{7}$ who reported a significant association of snoring and observed apnoeas in subjects with asthma-related symptoms. In another questionnaire study, Larsson et al. ${ }^{8}$ reported that asthma was related to snoring and witnessed apnoeas, but not daytime sleepiness. These associations were not confirmed, however, in other population-based studies. Klink et al. did not find a significant association between excessive daytime sleepiness and asthma. ${ }^{9,20}$ However, in questionnaire-based studies, non-specific symptoms such as cough and wheeze could have been attributed to different causes besides asthma, including COPD. Moreover, it is possible that the link between asthma and snoring might simply be due to the presence of upper airway inflammation that is common in asthmatic patients. The difference between our study and the aforementioned ones is that the diagnosis of asthma was based on strict criteria and the clinical judgement of a respiratory physician. The absence of a plausible common underlying pathophysiologic mechanism between asthma and OSAHS further supports the absence of association between the two conditions.

Patients with hypertension or CVD were more likely to present excessive daytime sleepiness and frequent snoring. Our data are in agreement with previous studies reporting association between OSAHS and hypertension, both in young and elderly patients. ${ }^{21}$ Moreover, frequent snoring has also been associated with CVD in large epidemiologic studies, with similar odds ratios to the present study. ${ }^{22}$ Patients with stroke were also more likely to present frequent snoring in our study, in agreement with data from the Sleep Heart Health Study. ${ }^{5}$ Interestingly, breathing pauses in our study were not associated with a history of CVD, stroke and hypertension, in contrast with a recent study by Teculescu et al. which reported a significant association between breathing pauses and a history of stroke or hypertension. ${ }^{23}$ However, the findings of the latter study were not based on a community sample but only in active men and only $5.4 \%$ reported breathing pauses. Furthermore, $46.6 \%$ of the studied sample was bus drivers and there could be an underestimation of their symptoms. In our study $13.7 \%$ of men and $7.1 \%$ of women presented breathing pauses. A potential limitation of our study might be the fact that the presence or absence of breathing pauses in a significant proportion of our patients was self-reported and not always confirmed by the bed-partner.

Another potential limitation of the present study was that polysomnography was not performed for OSAHS diagnosis. Although this is the gold standard for the diagnosis of sleep apnoea, it is a costly method not suitable for screening in primary care. In the era of increasing demand for sleep studies, the identification of target groups for the application of simple questionnaires for the screening of OSAHS in the primary care setting is invaluable. Our study provides evidence that, besides patients with cardiovascular disorders, COPD patients should also be screened for OSAHS-related symptoms in primary care.

Finally, another limitation of the present study is the fact that the presence of co-morbidities was self-reported by the patients. However, in the majority of cases the medical records of each patient and the medication that he or she was receiving were reviewed in order to confirm the corresponding diagnoses.

In summary, this is the first large epidemiological study conducted in Greece which reports the prevalence of symptoms related to sleep apnoea and assesses their correlation with physician-diagnosed asthma and COPD. Our study has obtained a rather high prevalence of snoring, witnessed breathing pauses and daytime sleepiness, symptoms which present a high pre-test probability for OSAHS. The increased likelihood for OSAHS-related symptoms in COPD patients, in contrast with asthmatic patients, designates them as another target group for the screening of OSAHS in the primary care setting.

\section{Acknow ledgements}

The authors wish to thank Drs C. Chatzoglou, K. Christou, C. Daenas, I. Gerogianni, A. Katsampeki, T. Kerenidi, V. Kouloumenta, M. Kouri, A. Koutsokera, M. Minas, E. Papageorgiou, A. Papaioannou, M. Papala, K. Tanou, C. Terzoudis, and V. Tsolaki, for their help with the collection of the questionnaires and spirometry testing. 
Additionally, they wish to thank Ms E. Souloukou and Ms A. Toutoudaki for secretarial support throughout the study.

\section{Conflict of interest statement}

There were no conflicts of interest for the authors in the preparation of this paper.

\section{References}

1 Stradling JR, Davies RJ. Sleep. 1: Obstructive sleep apnoea/hypopnoea syndrome: definitions, epidemiology, and natural history. Thorax 2004;59:73-8.

2 Schlosshan D, Elliott MW. Sleep. 3: Clinical presentation and diagnosis of the obstructive sleep apnoea hypopnoea syndrome. Thorax 2004;59:347-52.

3 Young T, Evans L, Finn L, et al. Estimation of the clinically diagnosed proportion of sleep apnea syndrome in middle-aged men and women. Sleep 1997;20:705-06.

4 Kushida CA, Nichols DA, Simon RD, et al. Symptom-based prevalence of sleep disorders in an adult primary care population. Sleep Breath 2000;4:9-14.

5 Shahar E, Whitney CW, Redline S, et al. Sleep-disordered breathing and cardiovascular disease: cross-sectional results of the Sleep Heart Health Study. Am J Respir Crit Care Med 2001;163:19-25

6 Larsson LG, Lundback B, Jonsson AC, et al. Symptoms related to snoring and sleep apnoea in subjects with chronic bronchitis: report from the Obstructive Lung Disease in Northern Sweden Study. Respir Med 1997;91:5-12.

7 Ekici A, Ekici M, Kurtipek E, et al. Association of asthma-related symptoms with snoring and apnea and effect on health-related quality of life. Chest 2005; 128:3358-63.

8 Larsson LG, Lindberg A, Franklin KA, et al. Symptoms related to obstructive sleep apnoea are common in subjects with asthma, chronic bronchitis and rhinitis in a general population. Respir Med 2001;95:423-9.

9 Klink M, Quan SF. Prevalence of reported sleep disturbances in a general adult population and their relationship to obstructive airways diseases. Chest 1987: 91:540-6.

10 Young T, Peppard PE, Gottlieb DJ. Epidemiology of obstructive sleep apnea: a population health perspective. Am J Respir Crit Care Med 2002;165:1217-39.

11 Netzer NC, Stoohs RA, Netzer CM, et al. Using the Berlin Questionnaire to identify patients at risk for the sleep apnea syndrome. Ann Intern Med 1999;131:485-91. 12 Johns MW. A new method for measuring daytime sleepiness: the Epworth sleepiness scale. Sleep 1991;14:540-5.

13 Standardization of Spirometry, 1994 Update. American Thoracic Society. Am J Respir Crit Care Med 1995;152:1107-36.

14 Global Initiative for Chronic Obstructive Lung Disease. Global Strategy for the Diagnosis, Management and Prevention of Chronic Obstructive Pulmonary Disease. NHLBIMHO workshop report. Bethesda, National Heart, Lung and Blood Institute, April 2001; Update of the Management Sections, GOLD website (www.goldcopd.com). Date updated: 1 July 2003.

15 Kostikas K, Gaga M, Papatheodorou G, et al. Leukotriene B4 in exhaled breath condensate and sputum supernatant in patients with COPD and asthma. Chest 2005; 127:1553-9.

16 Chaouat A, Weitzenblum E, Krieger J, et al. Association of chronic obstructive pulmonary disease and sleep apnea syndrome. Am J Respir Crit Care Med 1995; 151:82-6.

17 Resta O, Foschino Barbaro MP, Brindicci C, et al. Hypercapnia in overlap syndrome: possible determinant factors. Sleep Breath 2002;6:11-18.

18 Sanders $M H$, Newman $A B$, Haggerty $C L$, et al. Sleep and sleep-disordered breathing in adults with predominantly mild obstructive airway disease. Am J Respir Crit Care Med 2003;167:7-14

19 Wetter DW, Young TB, Bidwell TR, et al. Smoking as a risk factor for sleepdisordered breathing. Arch Intern Med 1994;154:2219-24.

20 Klink ME, Dodge R, Quan SF. The relation of sleep complaints to respiratory symptoms in a general population. Chest 1994;105:151-4.

21 Nieto FJ, Young TB, Lind BK, et al. Association of sleep-disordered breathing, sleep apnea, and hypertension in a large community-based study. Sleep Heart Health Study. JAM A 2000;283:1829-36.

22 Hu FB, Willett WC, Manson JE, et al. Snoring and risk of cardiovascular disease in women. J Am Coll Cardiol 2000;35:308-13.

23 Teculescu DB, Hannhart B, Benamghar L, et al. Witnessed breathing pauses during sleep: a study in middle-aged French males. Respir Med 2005;99:1268-74.

\section{Available online at http://ww w.thepcrj.org}

